\title{
Secondary School Needs in Remote Experimentation and Instrumentation
}

\author{
http://dx.doi.org/10.3991/ijoe.v8iS3.2269 \\ O. Dziabenko, and J. Garcia Zubia \\ University of Deusto/Deusto Tech Learning, Bilbao, Spain
}

\begin{abstract}
The education in applied sciences, engineering, and technologies is one of the Key Competences for Lifelong Learning (2006/962/EC) and priority areas in the educational strategy in EU countries. It directly effects the industrial development. Recent surveys show that the occupational structure of EU employment of the engineering sector tends to shift towards knowledge- and skills-intensive jobs from $27.3 \%(2007)$ to $32.4 \%(2020)$ (CEDEFOP, Skills supply and demand in Europe. Medium-term forecast up to 2020 (2010)). Therefore, contemporary industry demands well-educated STEM (Science, Technology, Engineering and Mathematics) graduates. Since students' motivation to learn depends upon the knowledge and skills of the teachers, teachers should have access to high quality and real-lifebased resources to build their competence, to support student's improvement, to familiarize with up-to-date research, development and industrial needs in STEM. This paper presents the study results on secondary school needs in development of remote experimentation and ICT competences in several EU countries. The survey was executed in frame of the project "OLAREX: Open learning approach with remote experiments” supported by EU Lifelong Learning Programme.
\end{abstract}

Index Terms-vocational training, ICT building competency, distance learning, secondary school remote experiments, e-learning.

\section{INTRODUCTION}

New Outlooks in Science \& Engineering survey shows that only $4 \%$ of teenage girls are interested in getting trained as engineers, and $14 \%$ as scientists, while $32 \%$ want to be fashion models [1]. At the same time CEDEFOP [2] introduces an occupational structure of EU employment of the engineering sector that tends to shift towards knowledge- and skills-intensive jobs from $27.3 \%(2007)$ to $32.4 \%(2020)$. These facts describe society needs for a new vision on quality and effectiveness of education and training systems to attract students to the STEM (Science, Technology, Engineering and Mathematics) disciplines. It achieves by building up-todate e-didactic and technology competences for professionals who pedagogically support formal and nonformal learning; and providing the students with multimedia interactive e-learning courses including an experimental laboratory. The fundamental benefit of experimenting is encouraging students for innovation and creativity. However, the traditional laboratory equipment is expensive and its maintenance is complicated. It is a cause of laboratories lack in universities, colleges [3] as well in secondary schools. The remote laboratory reduces the costs significantly, makes lab experiments available almost at any time and everywhere, personalizing the learning pathways [4], [5]. Updating curriculum of secondary education study programs by including new elearning approaches is one of the key issues in modernization and enhancing of STEM program of studies. The task of curriculum designing is to ensure the quality of curriculum parameters, as well as to create learning situations engaging students in learning and assisting them to measure their progress. Therefore, learning environment and opportunities, pedagogical support, and methodology that will encourage STEM learners have to be improved by updating and establishing new curricula, introducing new practical experiences for students, linking to the innovative elements in ICT use, e.g. integration remote and media experiments.

Observing the tendency of decrease in the interest in STEM studies and understanding the demand for well educated individuals for the EU industry, the researchers and secondary schools teachers from six EU countries Austria, Bulgaria, Hungary, Lithuania, Poland and Spain unite their efforts to reconsider new strategies in the STEM educational field:

- to analyze the curriculum needs in terms of schooluniversity-industry requirements;

- to develop e-didactic competences for STEM teachers and provide them with remote laboratories' access and remote experimentation places to deepen their knowledge and skills;

- to engage the non-formal educators - museum exhibition designers - in technology, engineering, and remote-experiments activities by improving their knowledge and skills in these fields;

- to motivate students by up-to-date developed elearning material with remote experiments, the museum provocative activities, and linkage to the enterprises.

The paper presents the results of first stage of activities suggested above - the study of ICT curriculum and knowledge needs of secondary school for six European country.

\section{GENERAL INFORMATION}

The main aims of the study were to analyze:

- knowledge and skills needs requested from secondary school students to successful transition in higher education or high-grade vocational training or to start a career, and for university students as a future employees in industry;

- e-learning materials and remote experiments needs and education methods. 
In order to reach the above aims four different groups: secondary school and university students, secondary school teachers, management and administrative staff of secondary schools and industry will be questioned over online survey. However, the primary target audiences of the study are students and teachers of secondary schools. The survey was organized in six EU countries - partners of OLAREX project - Austria, Bulgaria, Hungary, Lithuania, Poland and Spain. In the survey were participated overall more than 1000 students (about 300 students from Austria, more than 450 students from Spain, more than 100 students from Hungary, etc.), around 320 secondary school teachers, more than 60 representatives of secondary school administration, such as directors, headmasters, and leaders of the subject departments, and finally, around 40 representatives of managing staff of industry.

\section{STUDENT PROFILE}

The students participated in the survey can be represented in two groups: secondary school students and freshman university students. The age range of students is between 14-18 years old for secondary schools and 19-21 years old for the university. Most of the students can communicate and study in English. Comparing to the other participated European countries only $80 \%$ Polish and Lithuanian responded students can study in English (Fig.1).

Most students have an access to Internet at home and at school -classroom or library. After PC and Laptop on the frequency of Internet connection, Smartphone stays on the second place. Usually students use Internet for personal communication (email) and social networking (Facebook, Twitter, etc.). Students seldom use ICT for the learning purposes. For, example for learning 35\% of Spanish responders use Office applications, $12 \%$ use GoogleDocs and less than $50 \%$ use LMS. Only $40 \%$ of Bulgarian students, $30 \%$ of Spanish and Polish ones, and $10 \%$ of Austrian, Lithuanian and Hungarian responders have heard about the open courseware or free online lectures. These numbers show researchers that students use ICT tools mostly for entertainment purposes and a strategy shall be developed to engage students for using ICT in lifelong learning setting. Although most responders never heard about remote experiments before, they like to try something new and are interested to use remote experiments in the classroom (Fig.2).

\section{TEACHER PROFILE}

The teachers participating in survey have Master in Education or equivalent education (around 90\%), with more than 10 years of experience. If in Austria and Spain gender presentation will be approximately equal - 46\% females and $54 \%$ males, in other countries the percentage of female participation in survey was much higher $-79 \%$ in Hungary, more than $95 \%$ in Bulgaria and $82 \%$ in Lithuania. Around of half of participants have sufficient knowledge to study and communicate in English. All participants believe that their competencies for the tasks at their job are good or satisfactory sufficient: they can quickly learn and adapt new teaching methods, learn and adapt new technology for education, find and evaluate the ICT tools, and able to design course with online assignment. However, at the same time there is a solid de-

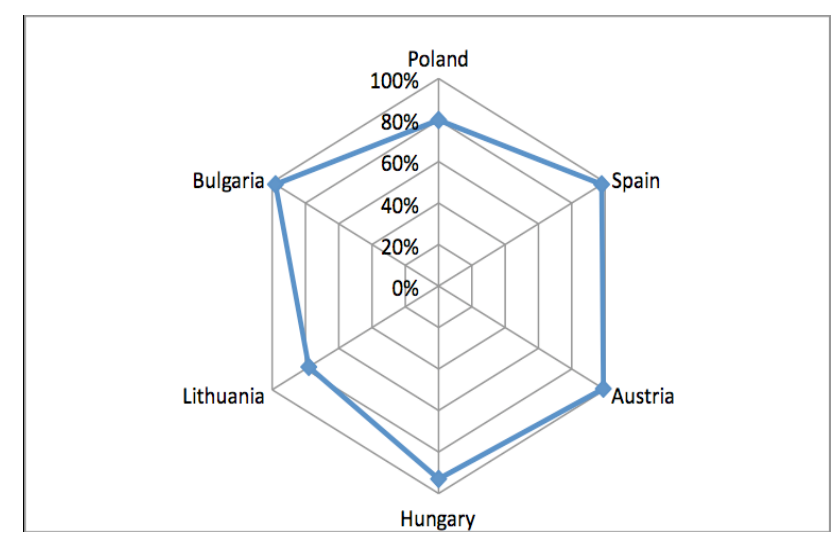

Figure 1. Ability of students to communicate and study in English

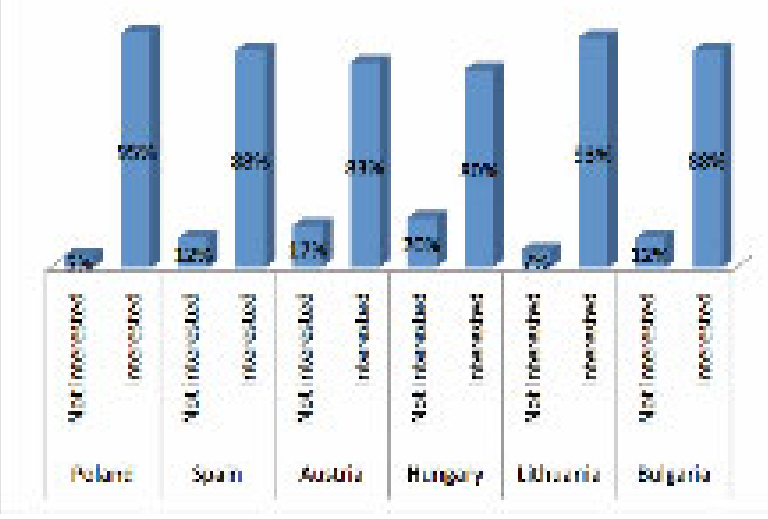

Figure 2. Remote Laboratory: students' interest in usage

mand ( $40 \%$ of responders) of training in order to be more efficient in new technology and teaching methods. Most have very good and good basic knowledge and skills in use: hardware (plotter, scanner, and digital devices), email and Internet research, the Microsoft Applications: Word processing, Excel, Power Point programs.

However at the same time, most participants shared their concern that their knowledge of ICT implementation in classroom, and organizing collaborative e-activity with students are insufficient and inadequate. More than $70 \%$ are actively participants in the social networks: Facebook $(50 \%)$, Twitter (17\%), Google+ (12\%). 43\% participate in forums and particularly professional forums.

$77,4 \%$ of participants regularly participated in traditional trainings and $68 \%$ have already experience in online trainings. $70 \%$ of all participants use Internet as a source of continuing education. Very often "courses organized outside of the school" (69\% paid by the school and $36 \%$ paid by the teachers) and seminars $(28 \%)$ are education source also. Although more than $80 \%$ of the teachers have not heard about remote laboratories, they would be interested (more than 95\%) in them if this instrument will be available in their school.

\section{School Profile}

The school profile is based on the responses of administrating and managing staff of the secondary school. All schools have good Internet connection and sufficient equipment support - can offer approximately 20 computers for education purposes. In general, over 5 years 
the ICT have been used in schools of responded countries. The Microsoft collection is most used software and support available for administration and education, e.g. Word processing $(100 \%)$, e-mail $(96 \%)$, and Spreadsheet/Excel (85\%). Schools can provide a few of education application in Mathematics, Technology, Science, and English. Twenty different statements of obstacles of using ICTs for education purposes were proposed for response to administrative staff. Despite on the different gaps in different participant countries the responders are agreed that "Insufficient number of computers and peripherals (printers, scanners, etc.)", "Lack of funds", "Not enough training opportunities for teachers", "Teachers lack knowledge/skills in using computers/the Internet for instructional purposes", "No time in teachers' schedules to explore opportunities for using computers/Internet", "Insufficient time for teachers to prepare ICT-based lessons" influence on the development of ICT competence of secondary school teachers. More detailed information is presented in a report on the official project webpage [6].

The laboratory practical components are offered in classroom in all countries. Mostly lab experiments are implemented in Chemistry and Physics curriculum. 58\% of questioned school administrative staff has heard about remote laboratory and experimentation. In all countries we got significant percentage of wish to participate in pilot project of using remote laboratory in classroom.

\section{KNOWLEDGE NEEDS}

The main purpose of the study was to understand the ICT knowledge gap in displayed countries. The analysis was based on the responses of secondary school teachers, their leaders - headmasters and directors and representatives of industry- SMS and large enterprises. We have interested: what special skills need teachers from their view point and from point of decision making people; what ICT knowledge needs for the students from "school" and from the "industrial" as a future employer view point. All courses presented during survey can be divided on five topics:

- Remote experiments: introduction and integration to curriculum

- Evaluation of e-learning materials, ICT tools and applications

- Virtual learning : LMS and virtual mobility

- ICT museum programs in the classroom

- ICT for school management and professional development.

Based on the answers of the teachers and their administration, the most attract courses are "Designing curriculum for Moodle virtual learning environment" and "Empowering education: How choose ICT instruments and applications for purpose of your curriculum". The results on the course "Transforming curriculum with remote experimentation: how to integrate it in secondary school classroom" are presented on Fig.4.

As shown we got promising picture of teachers' interest to get knowledge and try the remote labs in the classes. According the decision making representatives, for their teachers they would recommend all training topics listed in the questionnaire except the international virtual mobility. However, most in all countries they would not

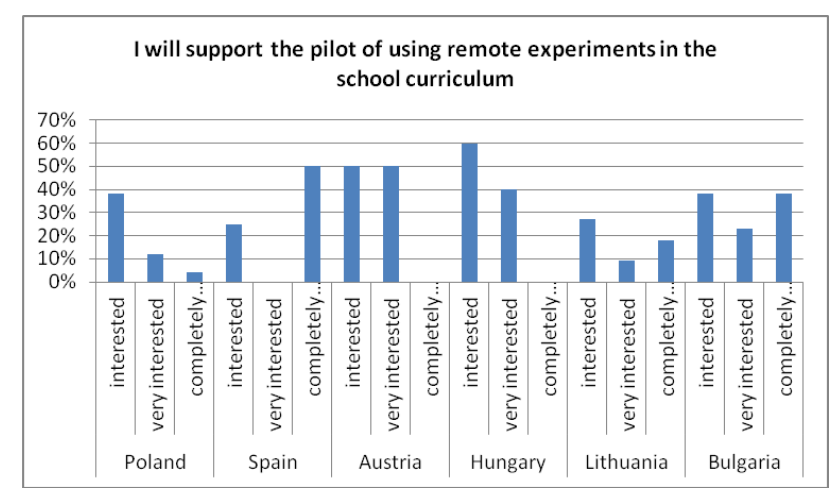

Figure 3. Remote Laboratory: interest of secondary school administrative staff

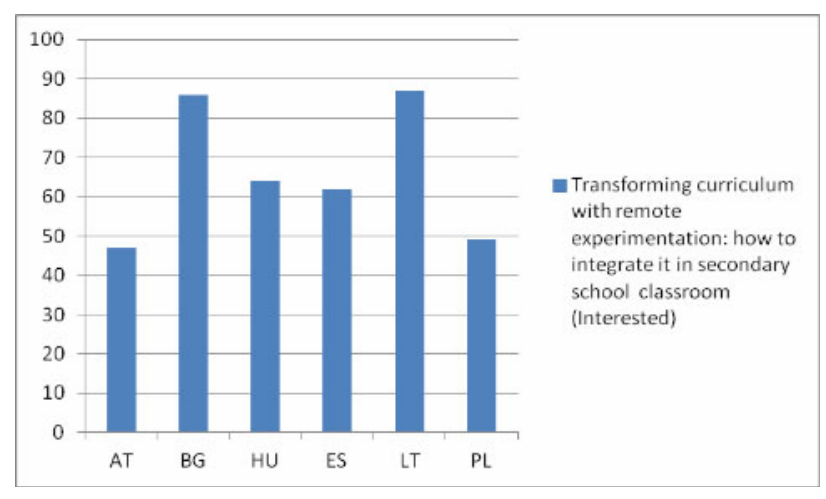

Figure 4. Integration Remote Laboratory in a classroom: interest of secondary school teachers

be able to support the teachers in their participation in OLAREX trainings. Teachers will need strong selfcommitment and motivation to participate in the training.

\section{CONCLUSION}

Based on the survey results we can conclude that there is a need in generally introducing the pedagogical and technical concept of remote experiments in participated countries. Mainly a large percentage of the students and teachers are not aware of the ICT application: remote laboratory, most of them do not even know the definition or the educational and technical concept behind. Therefore, more theoretical, informative material on that subject matter should be useful for presentation and access. At the same time the general interest is high regarding remote experiments. There are no doubts that this tool should be implemented in the school curriculum. Almost $100 \%$ of survey participants believe that remote labs can enhance the practical components of science curriculum in their schools.

\section{ACKNOWLEDGMENT}

This work has been performed within the project "OLAREX: Open Learning Approach with Remote Experiments". The project is supported by European Union within KA3 (ICT) activity of Lifelong Learning Programme (project No. 518987-LLP-1-2011-1-ES-KA3KA3MP). The opinions expressed by the authors do not necessarily reflect a position of the European Community, nor does it involve any responsibility on its part. 


\section{REFERENCES}

[1] M. Gould, "Girls choosing camera lenses over microscopes", The Guardian.(Oct.03,2008), http://www.guardian.co.uk/education/ 2008/oct/03/science.choosingadegree (accessed March 12, 2012)

[2] CEDEFOP, Skills supply and demand in Europe: medium-term forecast up to 2020, http://www.cedefop.europa.eu/EN/publi cations/15540.aspx (accessed March 12, 2012)

[3] Kostulski, T., Murray, S., (2010). The National Engineering Laboratory Survey. Sydney: Labshare, available at: http://www.labshare.edu.au/community/white/ (accessed March 15, 2012)

[4] Rodriguez-Andina, J.J.; Gomes, L., and Bogosyan, S. "Current trends in industrial electronics education" IEEE Trans. Industrial Industrial Electronics, $N^{\circ}$ 57, VOL 10, pp: 3245-3252, October 2010

[5] Gomes, L., and Bogosyan, S "Current trends in remote laboratories"' PIEEE Trans. On Industrial Electronics, $n^{\circ} 56$, VOL 12, pp: 4744-4756, December 2009.
[6] OLAREX: Open Learning Approach with Remote Experiments, available at: http://www.olarex.eu/web/index.php/en/products (accessed June 10, 2012)

\section{AUTHORS}

O. Dziabenko is with the University of Deusto, Deusto Tech Learning, Avda de las Universidades 24, 48007 Bilbao (e-mail: olga.dziabenko@ desuto.es).

J. Garcia Zubia, is with the University of Deusto, Faculty of Engineering, Avda de las Universidades 24, 48007 Bilbao (e-mail: zubia@deusto.es).

This article is an extended and modified version of a paper presented at the International Conference on Remote Engineering \& Virtual Instrumentation (REV2012), held at University of Deusto, Bilbao, Spain, July 4-6, 2012. Received 14 September 2012. Published as resubmitted by the authors 14 November 2012 . 